\title{
Questões de gênero na Educação Física escolar
}

\author{
O professor diante das relações \\ de gênero na Educação Física \\ Escolar. \\ CORSINO, Luciano Nascimento; AUAD, \\ Daniela. \\ São Paulo: Cortez, 2012. 111 p.
}

O autor e a autora convidam o/a leitor/a a refletir sobre professores e professoras diante das relações de gênero, com base em observações realizadas em escolas públicas de São Paulo, durante as aulas de Educação Física, dentro da proposta teórica dos estudos de Joan Scott, Claude Zaidman, Heleieth Safiotti, Linda Nicholson, Valerie Walkerdine, Cristine Delphy e Carol Giligan.

No primeiro capítulo, cujo título é "Relações de Gênero, Educação e Educação Física", ressaltam que ocorre um processo de hierarquização em relação ao feminino e masculino a partir das relações de poder que se estabelecem no ambiente da Educação Física. Assim tal ocorre em diferentes momentos das aulas, como na forma de organização e tratamento dos conteúdos e, em especial, nas relações entre alunos e alunas e professoras/professores e alunos/alunas.

Esclarecem que a diferença hierarquizada compreende um ato social que consiste em re(conhecer), hierarquizar e transformar a diferença em desigualdade. Propõem três perguntas: como os docentes misturam ou separam os/as estudantes? como as atividades realizadas em aula podem reforçar diferenças hierarquizadas entre feminino e masculino mantendo desigualdades de gênero entre os sexos?; como a forma que se lida com a corporeidade de meninos e meninas se relaciona com construções de gênero elaborada na realidade escolar tanto por estudantes quanto por docentes?

Com essas perguntas, desenvolveram uma pesquisa em uma escola pública de São Paulo, cujo codinome Escola do Princípio Ihe foi atribuído. A instituição oferece ensino médio e ensino fundamental nos turnos matutino, vespertino e noturno e conta com quatro professores de Educação Física, dos quais há apenas uma mulher.

No segundo capítulo, "Pesquisas sobre um tema nem atual assim", elucidam que os estudos de gênero na Educação Física não são recentes, pois se intensificaram a partir do final da década de 80 , apoiados por diferentes abordagens das Ciências Humanas, Sociais e Biológicas. Caracterizavam-se, principalmente, por denunciar uma Educação Física Escolar baseada em preceitos médicos, militares e esportivos que não condiziam com uma educação que proporcionasse uma aprendizagem significativa, contemplando todos os sujeitos.

Nesse ponto, é realizada uma pequena revisão teórica a fim de demonstrar que a área começou a se transformar sob a influência dos estudos feministas e culturais. Alguns autores passaram a considerar que a Educação Física possuía potencial pedagógico para desconstruir concepções de feminilidade veiculadas na mídia e se debruçaram em analisar as diferenças que se constituem dentro do espaço da escola, aspectos e convenções estabelecidas a respeito do corpo, divisões entre atividades que seriam naturalizadas como de menina ou de menino.

Ao final do capítulo, propõem um projeto igualitário, que torne as vivências corporais não enclausuradas em ideais e modelos para ambos os sexos, que proporcione a desconstrução da noção de habilidade inata e questione paradigmas e práticas consolidadas na área da Educação Física Escolar.

Em "A igualdade de gênero e a Educação Física Escolar", apoiam a escola mista, considerando, no entanto, que misturar meninos e meninas não basta, pois ainda é necessária a orientação baseada em políticas públicas que proporcionem igualdade. Ponderam que a área é historicamente marcada por separações entre meninos e meninas e apresentam a "Coeducação" como alternativa.

Tal conceito consiste em favorecer atividades conjuntas entre meninos e meninas; proporcionar outros significados às modalidades que apresentam certas características, como o rendimento; dar importância à participação do/a professor/a, que deve dispensar tratamento igual para meninas e meninos, fazendo as mesmas exigências para ambos; aproveitar eventuais situações ocorridas durante as aulas para problematizar as questões de gênero.

Indicam que um dos possíveis caminhos para a adoção da Educação Física Coeducativa seria a consideração das teorias pós-estruturalistas, 
que contribuem para a desconstrução de determinadas representações tidas como "a verdade" e, assim, redefinir relações de gênero desiguais no ambiente escolar.

No início do capítulo "Misturas e separações", resgatam que os estudos de gênero de orientação pós-estruturalista e estudos culturais auxiliaram a perceber a escola como instituição marcada por práticas discursivas, configurandose como campo de lutas simbólicas e relações de poder. Afirmam que são relações explícitas que podem ser verificadas também no silêncio ditam o que é ser homem ou mulher e podem ser questionadas no cotidiano.

Nas observações realizadas na Escola Princípio, mencionada anteriormente, os pesquisadores perceberam que relações de gênero nas aulas de Educação Física são marcadas por uma aprendizagem do silenciamento, em que não se discute sobre essa questão. Essa condição possibilita um ambiente pacífico, com aulas tranquilas, mas contribui para a construção de identidades conformistas em relação às assimetrias de gênero no espaço escolar.

Os/as professores/as da referida escola dividiam as aulas em práticas (na quadra) e teóricas (em sala de aula). Nesta, os/as estudantes sentavam de acordo com seus grupos de costume, os professores não exigiam nem faziam maiores considerações sobre isso, e meninos e meninas misturavam-se naturalmente. Notaram, porém, práticas discursivas que não foram dialogadas com as turmas, como brincadeiras e ironias de cunho machista, em que um menino, ao ironizar que não gostava de futebol porque preferia brincar de bonecas coloca a atividade atribuída ao sexo oposto como algo pejorativo e que "naturalmente gostava de futebol por ser homem".

Advertem que as práticas detectadas não eram voltadas para as meninas, e sim para os meninos. São construções de gênero elaboradas em grupos formados por meninos no sentido de reforçar desigualdade, marcando entendimentos sobre o que é idealmente masculino ou feminino.

Nas atividades realizadas no pátio, observam e relatam que havia um duplo discurso da instituição, pois, ao falar sobre alunos e alunas, não faziam diferenciação, pois utilizavam os termos "alunos" ou "classe", optando pela neutralidade e masculino genérico, desconsiderando os sexos masculino e feminino dos sujeitos. Concluíram, portanto, que há a necessidade de uma participação docente mais ativa para desconstruir as práticas detectadas.

No capítulo "Conteúdo das Aulas", verificam que, na Proposta Curricular do Estado de
São Paulo, a disciplina de Educação Física consta categorizada na perspectiva "culturalista", baseada nas Ciências Humanas e Sociais, inserindo uma cultura do movimento representada por danças, artes marciais/lutas, ginásticas e exercícios físicos. Envolve também a importância de considerar as culturas juvenis e dar espaço para o hip-hop, a capoeira, as artes marciais, o skate. a musculação e outras.

Durante as observações na Escola Princípio, notaram que há distanciamento dessa proposta, mas há a presença de alguns temas relacionados a determinadas modalidades esportivas, como no atletismo, modalidade em que não havia muitas assimetrias, o que proporcionou um equilíbrio nas relações de gênero, pois meninas e meninos recebiam números de 1 a 4 , aleatoriamente, e os grupos eram formados pelos conjuntos de todos os números 1, 2 e assim sucessivamente.

No entanto, durante o aquecimento, notaram discursos do tipo: "hoje os meninos estão pior do que as meninas, hein?", discurso esse oriundo de uma aluna, algo que não é discutido pela turma nem pelos docentes. Em contraponto ao atletismo, em que se reduziam de alguma forma as desigualdades, nas aulas de futebol, maioria durante a observação, o esporte não era discutido em sala de aula, partindo do pressuposto de que todos sabem do que se trata.

Meninos e meninas jogavam separadamente. Meninos começavam e havia um tempo determinado para o jogo, ao final, deveriam sair da quadra para que as meninas jogassem. Disso derivavam vários conflitos, entre meninos e meninas, com um discurso desqualificador e machista por parte deles. A mistura de estudantes no sentido de integrar não era orientada. As meninas queixavam-se de que os meninos eram violentos, e os meninos reclamavam que as meninas não sabiam jogar.

Foram trabalhados ainda o handebol e o vôlei, mas de maneira eminentemente teórica Os esportes não eram discutidos no sentido de proporcionar reflexões, e a única modalidade que foi estruturada de maneira que se pudesse promover alguma igualdade de gênero foi, de fato, o atletismo.

No sexto capítulo, denominado "Resistências e Conflitos", o autor e a autora afirmam que a Educação Física Escolar é palco de resistências e aceitações. Assim, apontam para a importância de perceber as relações desiguais de gênero que se estabelecem e que se tornam explícitas, por sua construção histórica, baseadas em preceitos biológicos e higienistas.

Corsino aduz que, na Escola Princípio, percebeu, em diversos momentos, os movimentos de 
resistência, tanto na linguagem verbal quanto na não verbal. Citaram alguns exemplos como momentos em que as meninas reivindicavam o direito de participar dos jogos de futebol com os meninos; quando meninas negavam-se a jogar vôlei; quando queriam jogar futebol; e quando um menino, considerado "afeminado" pelos demais, impõe-se pressionando o professor a inserilo no jogo de futebol ou, caso contrário, iria reclamar na direção da escola.

Consideram que é fundamental misturar meninos e meninas para as atividades em Educação Física, defendem uma política educacional coeducativa, apontam para a necessidade de dar atenção aos conteúdos, evitando privilegiar um ou outro esporte, como realizar sempre aulas de futebol em detrimento de outras modalidades esportivas. Propõem ainda uma reflexão sobre como meninas e meninos interiorizam ou não o que é constantemente disseminado pelas práticas discursivas sobre papéis de gênero. Afirmam que as identidades são constituídas nos jogos de relações de poder, produzindo diferentes efeitos, como os conflitos de gênero verificados nas aulas.

Classificaram as situações relacionadas no estudo como "jogo das resistências e aceitações" e que os conflitos durante as aulas misturadas são mais explícitos e intensos, mas que são momentos privilegiados para que os professores possam problematizar as relações de gênero em suas aulas. Professores buscam evitar os conflitos, mas, na realidade, tratam-se de atos de resistência de meninas e meninos às fronteiras de gênero tradicionalmente impostas na sociedade.

No capítulo Perguntas e respostas coeducativas, há três questões que são propostas a partir do estudo da Escola Princípio, bem como suas respostas. A primeira pergunta consiste em dizer como os docentes separam ou misturam alunos e alunas durante as aulas de Educação Física naquela escola. Constataram que as representações de alunos/as e docentes sobre gênero definem que as turmas separadas são melhores para o rendimento das aulas, e essa prática gera uma forma de silenciamento de conflitos. Mas, apesar dessa conduta, os professores não conseguiram fugir dos conflitos. As formas de separar ou misturar estudantes nas aulas de Educação Física dependiam da característica de cada professor. A forma de organização estava pautada por binarismos. Haveria a necessidade de realizar as misturas e discutir os conflitos resultantes delas.

A segunda questão estava voltada para responder como as atividades desenvolvidas podem reforçar diferenças hierarquizadas entre o feminino e masculino. Nesse sentido, autor e autora apontam que, durante a maioria das aulas observadas, não foi possível perceber o tratamento da Proposta Curricular do Estado de São Paulo - Educação Física, que é o documento norteador da ação docente. A maioria dos docentes utilizou os temas abordados no documento como tema de pesquisas solicitadas para que os/as estudantes tivessem conteúdo em seus cadernos a fim de que os pais não reclamassem das aulas de Educação Física. Os temas não eram abordados considerando os conflitos vivenciados em quadra, e os docentes justificavam essa sistemática com base na dicotomia teoria/ prática. Essa ausência de relação entre os conteúdos e as questões de gênero e corpo reforça e reproduz desigualdades.

A terceira questão era: como o lidar com a corporeidade de meninas e meninos, nas aulas de Educação Física, relaciona-se com as construções de gênero elaboradas na realidade escolar, tanto por alunos e alunas quanto pelos/as docentes? A resposta apresentada foi a de que os corpos são constituídos e apresentam marcas produzidas pelas relações de gênero na nossa sociedade. Os discursos produzidos por essas relações configuram características das pessoas. Entendem, portanto, que há a necessidade de existir, por parte de professores e professoras, diante da Educação Física Escolar, um aprofundamento dos conhecimentos sobre as relações de gênero. Sugerem que esse conjunto de saberes fosse desenvolvido inicialmente na graduação.

Clarice Gonçalves Pires Marques Universidade Federal do Rio Grande 